\title{
Importance of Internet of Things (IoT) in Marketing Research and Its Ethical and Data Privacy Challenges
}

http://doi.org/10.21272/bel.5(1).22-30.2021

Masoud Moradi, ORCID: https://orcid.org/0000-0002-0102-4085

$\mathrm{PhD}$, Assistant Professor, Department of Marketing, Texas State University, San Marcos, Texas, USA

\begin{abstract}
This paper focuses on examining IoT applications in marketing research and provides information on how organizations utilize IoT devices and other new technologies such as artificial intelligence (AI), machine learning (ML), and social media to promote various products and services. Moreover, this study specifies how the consistent use of IoT technologies results in substantial organizational competitiveness. The paper also explains how IoT can be referred to as a new component of business analytics and digital marketing and discusses the challenges related to introducing IoT solutions. The most pressing issues that need to be addressed in the IoT context are described as ethical and data privacy issues. It can be explained by the fact that a substantial amount of data is generated during the development of IoT solutions, which raises the question of whether the respective information could be properly managed. It necessitates implementing a transparent, ethical framework, which should be supported by an adequately regulatory process. The extensive exploration of IoT solutions allows academics and marketing practitioners to generate a wide range of data that can be used to improve products and services provided to diverse consumer groups. Therefore, this paper offers a framework for the collaboration process between academics and practitioners. This collaboration in developing IoT tools is marked by adopting a holistic approach to facilitating the progress of such innovation. Academic researchers' expertise can be utilized to generate creative and innovative ideas on the IoT sector. The combination of important theoretical assumptions and practical experience is vital to achieving the strategic goals of the collaboration between academics and practitioners.
\end{abstract}

Keywords: IoT, Marketing Research, Information Exchange, Organizational Competitiveness, Consumer Experience, Ethical Issues, Privacy Issues.

JEL Classification: L20, M15, M31.

Cite as: Moradi, M. (2021). Importance of Internet of Things (IoT) in Marketing Research and Its Ethical and Data Privacy Challenges. Business Ethics and Leadership, 5(1), 22-30. http://doi.org/10.21272/bel.5(1).22-30.2021.

Received: 02 January 2021

Accepted: 03 February 2021

Published: 30 March 2021

Copyright: (C) 2021 by the author. Licensee Sumy State University, Ukraine. This article is an open access article distributed under the terms and conditions of the Creative Commons Attribution (CC BY) license (https://creativecommons.org/licenses/by/ 4.0/).

\section{Introduction}

The Internet of Things (IoT) was initially accredited as a concept in 1999 to support Radio Frequency Identification (RFID) technology and interconnected computing devices. The range of devices comprises computers, smartphones, wireless sensor networks, home/building automation, manufacturing tools, software applications, and smart appliances (Lo and Campos, 2018). The collection, processing, and exchange of data through IoT allow consumers and organizations to acquire a wide variety of benefits. For instance, by adopting IoT devices, it is possible to diagnose, treat, and prevent diseases through electronic means (Vermesan and Friess, 2014). Moreover, it is attainable to integrate incorporate consuming appliances into one IoT system, enhancing the efficiency of power consumption (Ray, 2018). In marketing, smart appliances linked with IoT can track product supply, which eventually provides recommendations to the owners regarding new purchases, offers, and trends. Simultaneously, the number of IoT devices is expected to reach up to 30 billion by 2020 , as predicted by numerous researchers and IT experts.

Nowadays, IoT devices are used as a vital tool for marketing research. Organizations utilize IoT devices and other new technologies such as artificial intelligence, machine learning, and social media to promote various products and services (Lo and Campos, 2018). Specifically, IoT devices are adopted for communicating with customers, collecting marketing data, and evaluating marketing trends and performance indicators. The opportunities for IoT in business analytics are boundless (Vermesan and Friess, 2014). Numerous marketing 
and IT experts contend that the role of IoT in business analytics and marketing is less substantial in the current environment, though it has the potential to become considerable in the coming years (Orme, 2019; Ray, 2018; Vermesan and Friess, 2014). The practical development of IoT and digital marketing is quite progressive in comparison with its theoretical development. Therefore, there is a growing demand for additional scientific research to determine the multitude of opportunities, risks, and challenges associated with the role of IoT in marketing research.

This paper provides a review of the implementation of IoT in marketing research. IoT technologies are considered an innovative solution to improve the multiple parameters of organizational performance. It is illustrated in this article that the consistent use of IoT devices and applications leads to improved information exchange in marketing research. Moreover, the article discusses relevant details regarding IoT's potential to enhance organizational competitiveness in the global business environment. Finally, this paper presents information on the challenges associated with the use of IoT in marketing research. By exploring such challenges, individuals and practitioners in business research can improve their knowledge of existing IoT platforms and how they could utilize them for achieving optimal outcomes.

\section{Innovative Capacities of IoT in Marketing Research}

IoT can become a key instrument to enhance the aspects of marketing research. The technical capabilities of IoT can empower marketing managers to plan and carry out marketing research in a comprehensive manner (Pauget and Dammak, 2019; see Figure 1). Numerous factors should be considered to accomplish this research accordingly (Ray, 2018). For instance, convenience has become a strategic marketing tool, as it is a significant attribute of customer experience and the brand as a whole. In utilizing the IoT platforms for marketing research, the approach and communication methods allow marketing managers to establish a good rapport with consumers. IoT features such as Machine-to-Machine (M2M) communication, automation, and big data can swiftly assist marketing managers in identifying marketing opportunities and precisely segmenting the marketplace (Allhoff and Henschke, 2018). IoT can be referred to as a new component of business analytics and digital marketing. Organizations can offer a new product or service based on consumer market segmentation (Vermesan and Friess, 2014). This characteristic can also become a foundation for customercentric marketing (Pauget and Dammak, 2019). IoT devices tend to facilitate the advertisement process to become less inconvenient, as these technologies provide flexibility to the target audience to acquire a product or brand-related information (Moradi and Badrinarayanan, 2021) based on their choice and preference.

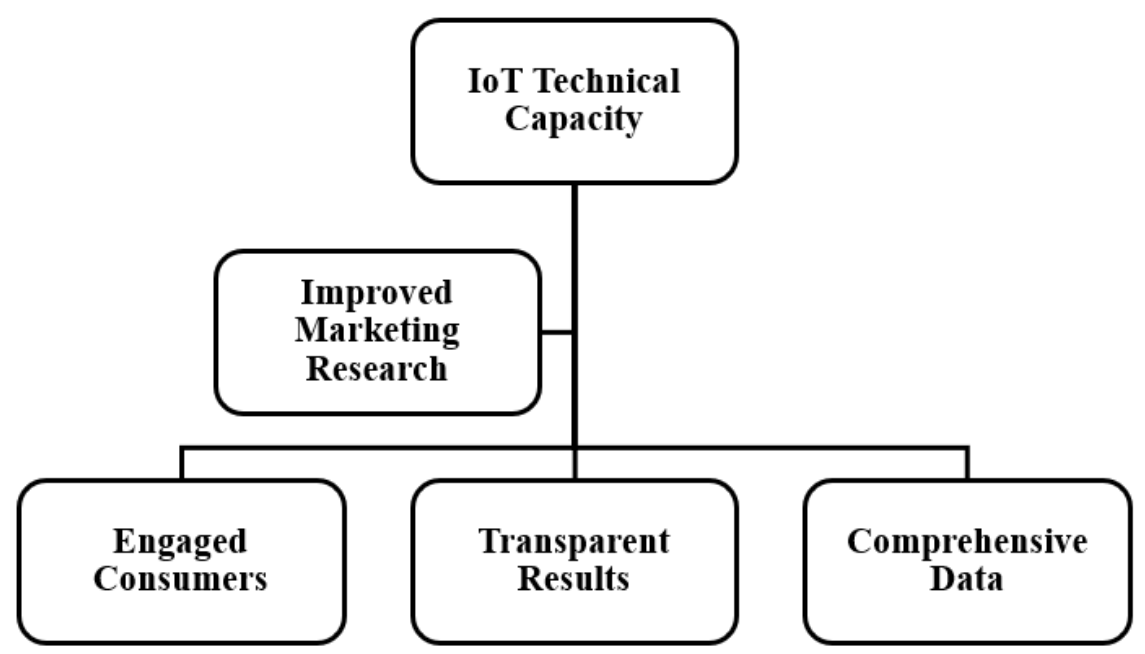

Figure 1. IoT in Marketing Research

Source: Developed by authors

In the context of communication, IoT platforms create a substantial number of new opportunities for organizations. IoT and social media can play a crucial role in expanding marketing channels and tools. Organizations are currently using social media to receive feedback on products and services (Ray, 2018). The integration of IoT technologies and social media can build a digital space where a company and a target audience can have closer rapport (Caro and Sadr, 2019). In addition to sharing personal data, the possibility of increasing the customer base is higher (Vermesan and Friess, 2014). Overall, IoT technologies might become an integral component of integrated marketing communications (IMC) and transform the overall architecture of business communication. 
Conducting marketing research is one of the main goals for a marketing manager. Acquiring big data with IoT devices for marketing research can create numerous opportunities, such as acquiring the desired audience, expanding the conversion rate, building brand awareness, and making swift business decisions (Ray, 2018). IoT platforms provide opportunities to gather consumer data in limitless volume, velocity, and variety. The type of data typically comprises age, gender, preferences, social status, income, interests, purchasing patterns, location, and other types of conduct (Pauget and Dammak, 2019). The opportunities related to market segmentation have become more comprehensive and powerful. Since the communication between interconnected computing devices is faster due to IoT use, industrial automation tools can help marketing managers rapidly obtain detailed and varying consumer behavior traits (Ray, 2018). As a result, this process significantly improves marketing research and organizational performance. A considerable number of consumers have already adopted modern technologies such as social media, gadgets, and smartphones to make purchasing decisions and facilitate their payment options.

Consumers are progressively showing more readiness to adopt mobile and wearable applications while shopping. This trend is particularly captivating for companies, as they can collect information about purchasing patterns and types of consumers (age, gender, social status, etc.) (Madakam et al., 2015). It will further help organizations develop qualitative and quantitative databases that might improve the product development process, supply chain method, advertising strategy, and marketing research. Organizations must emphasize the capacity of IoT platforms to pursue location-based consumer insights. One of the core components of marketing research (market information, market trends, data analysis, SWOT analysis, and PEST analysis) is market segmentation (Pauget and Dammak, 2019). It is of the most significant importance for organizations to recognize the segmentation of targeted customers. In the context of marketing research, IoT as a tool can help marketing managers integrate different factors in the analytical process to make data-driven decisions (Madakam et al., 2015). Organizations must gather quality data from effective marketing analytics, as it can maximize efficacy, performance, and optimal return on investment (ROI).

On the other side, some customers are concerned with the security and privacy issues linked with introducing new technologies. Considering the risks and hazards and challenges associated with the role of IoT in marketing research, security and privacy have become one of the key discussed issues (Vermesan and Friess, 2014). It has been observed that there is a considerable number of consumers who are ready to provide their personal information in exchange for product offerings, rewards, and vouchers (Ray, 2018). It has become a widespread tool for marketing managers to encourage consumers to share their personal information (Caro and Sadr, 2019). Yet, the security implications of this trend should be further explored to prevent customers' personal data misuse. The comprehensive scientific research on IoT can create additional opportunities to eliminate challenges and risks. It is important to consider users' consent initially to transfer data and connectivity plans and ensure their anonymity. The issue of anonymity is quite challenging, especially during the process of collecting personal information from consumers by marketing experts for promotional reasons.

The integration of IoT technologies to all aspects of marketing implies a relevant connection between consumers, mobile devices, and the Internet. In this context, the combination of various components in a single mobile application leads to increased efficiency and customer satisfaction (Caro and Sadr, 2019). The extensive use of IoT technologies enables companies to provide a wide range of products and services to clients. Individuals can select different options based on their interests and preferences; thereby, the notion of flexibility is adequately incorporated into IoT for marketing research (Pauget and Dammak, 2019). This type of research requires significant attention to the way information flows across specific networks and domains.

\section{Use of IoT to Enhance Information Exchange in Marketing Research}

In marketing research, considering the precise context in which customers use particular products or services is essential. The external environment and the conditions of using those products or services affect customer perceptions (Caro and Sadr, 2019). From this perspective, the sensed information obtained from customers' reactions is a vital source of feedback for organizations (Pauget and Dammak, 2019). Similar details are usually considered to detect the specific needs and preferences of individuals. Delivering a favorable customer experience is the primary concern of marketers. One way to satisfy customers in today's competitive business environment is to personalize the information delivered to them. It is essential to note that the process of information exchange should be represented by substantial value and meaning to those accessing the respective data (Gigli and Koo, 2011). A thorough consideration of individual expectations and preferences is needed to facilitate the overall scope of marketing research, helping companies gain more sustainable competitive advantages (Ray, 2018). Therefore, IoT technologies can be used to enhance information exchange in marketing research. A significant benefit of IoT, utilized in the marketing context, is the possibility to measure and monitor the emotional state of customers (Moradi et al., 2017) using specific products or services. 
Combining product empathic computing systems and sensors is frequently emphasized in research as an optimal solution to improve information exchange (Gigli and Koo, 2011). The mentioned systems can build distinct user models and ensure comprehensive, empathic responses about particular user trends (Pauget and Dammak, 2019). For example, the use of sensors in retail stores implies that such IoT technology helps serve customers better. Catering to the needs of individuals is an essential aspect of marketing research, and it refers to the dimension of personalization as well as to the concept of information exchange.

The data retrieved from IoT technologies flow from users to organizations, facilitating communication among significant stakeholders in a particular field. In turn, companies use the respective information to develop new, more efficient applications to serve customers' needs (Pauget and Dammak, 2019). The integration of IoT devices in marketing enables greater interactivity between marketers and users in accessing and evaluating specific information, which could be strategically used to benefit different groups of individuals (Kosmatos et al., 2011). Organizations' marketing departments receive relevant insights about customer experiences of specific products or services. Such feedback implies further possibilities for refinement and adjustment, which is in line with companies' utmost goal to deliver an optimal customer experience. Customers prefer to be adequately informed about the latest IoT trends, which implies that organizations are responsible for developing and maintaining a transparent process of information exchange. The aspects of transparency and open communication help individuals make relevant decisions based on detailed information about products or services (Kosmatos et al., 2011). IoT's multidimensional nature makes it possible for stakeholders to comprehend the implications of the consistently informed society of the 21st century (Gigli and Koo, 2011). Better informed stakeholders can propose better options for business development in line with the overall strategic direction and vision of organizations.

\section{Contributions of IoT Technologies to Organizational Competitiveness}

Since organizations tend to consider the multiple implications pertinent to the personalization of customer experience, the focus on enhancing organizational competitiveness is consistently maintained. It has been indicated that smart, connected devices and the information they generate have become fundamental for competition (Pauget and Dammak, 2019). The knowledge organizations gain about users' preferences and expectations is utilized in new marketing strategies and approaches to engage customers further (Ray, 2018). The exploration of sensing devices in the IoT context raises the question of how this process would impact organizational competitiveness. Biosensors' use to obtain relevant knowledge about customers' reactions is implemented as a strong foundation to gain competitive advantages. The possibilities implied with IoT technologies are limitless given the information that can be retrieved about individuals' intentions, actions, expressions, and even heart rate (Gigli and Koo, 2011). Combining all these details enables marketers to make more comprehensive inferences about current and future customer behavior trends (Vermesan and Friess, 2014). Thus, the development and adaptation of IoT are adequately taken into consideration, as the focus is not only on satisfying customers but also on comprehending specific changes associated with the force of competition.

Organizations are most likely to reconsider the existing conditions of competition to refine their current marketing strategy. As one of the dimensions of Porter's five-force model, the bargaining power of customers is emphasized when companies assess the implementation of IoT in marketing research to increase their competitiveness (Caro and Sadr, 2019). The insights obtained through IoT devices could either expand or reduce customers' bargaining power, especially when organizations are prompted to utilize new forms of market segmentation. At the same time, changing to a new supplier might impact users' satisfaction with particular products or services (Vermesan and Friess, 2014). Companies are expected to demonstrate a high level of strategic and market preparedness to address any changes that might occur in the process of integrating IoT technologies into marketing research. The implementation of IoT is commonly associated with significantly improved products and services that correspond to customers' needs and preferences. In this context, the functioning of organizations' marketing departments can enhance due to the added benefits from the IoT implementation (Vermesan and Friess, 2014). It means that customers might have additional reasons to purchase specific products, even though there could be a shift in power in the context of marketing research. Organizations usually emphasize building cross-functional teams from various business units to develop innovative and competitive IoT products and services (Caro and Sadr, 2019). The emergence of new IoT products is aligned with the organizational vision and strategy for long-term success.

\section{Development of IoT Tools and Challenges}

5.1 Collaboration between academics and practitioners in developing IoT tools. While organizational success is associated with introducing effective IoT tools, it is essential to consider the persistent collaboration between 
academics and practitioners in creating optimal strategies that could result in business excellence. In this context, referring to the collaborative IoT paradigm provides relevant insights into academics and marketing experts' involvement, emphasizing the idea of cooperation in data collection and analysis (Stankovic, 2014). The concept of service sharing is also improved due to such an ongoing collaboration (Rahman and Asyhari, 2019). It is assumed that academics demonstrate their extensive knowledge in gathering appropriate information that can be used in the development of comprehensive IoT tools. The collaboration between academics and practitioners in developing IoT tools is marked by the adoption of a holistic approach to facilitating the progress of such innovation. The reason for favoring such an approach is that academics can collect research information and interpret it from multiple perspectives (Farooq et al., 2015). They can share insights that can provide relevant strategic directions to marketing practitioners and IT specialists. Academic researchers' expertise can be utilized for the generation of creative and innovative ideas about the IoT sector (Wang et al., 2015). The combination of important theoretical assumptions and practical experience is vital to achieving the strategic goals of the collaboration between academics and practitioners.

The most significant message of academics regarding the utilization of IoT tools is related to harnessing the power of technology with the purpose of improving people's lives. Having this broad perspective in mind is a leading aspect of the collaboration between academics and practitioners in developing competitive IoT tools (Wang et al., 2015). As a result of this ongoing cooperation, innovative solutions can be presented to benefit different consumer groups. For instance, after a period of extensive research on the limitless potential of IoT applications, academics might devise effective IoT solutions to help people with speech disabilities (Suh, Seo, and Park, 2018). Once academics present their ideas, practitioners in a specific field would validate researchers. Such collaboration is apparently marked by high trust, open communication, and flexibility in the exchange of knowledge.

While communicating on the benefits of different IoT tools, academics and practitioners feel more empowered due to their commitment to shared objectives. Both sides need to be attentive to utilizing open communication channels to convey their ideas as effectively as possible (Wang et al., 2015). Being united by the intended results, academics and practitioners tend to value their cooperation since it can bring them in the desired direction (Angelova, Kiryakova, and Yordanova, 2017). The successful completion of particular projects involving IoT tools is the utmost objective of academics and practitioners, who might need a sufficient amount of time to reassess the strategic options for a meaningful change. The collaboration process between academics and practitioners is illustrated in Figure 2.

5.2 Research on consumer views on IoT solutions. Academics and practitioners are expected to consider consumer views on IoT solutions (see Figure 2), which is useful to build a body of trusted knowledge in this field. It has been indicated that consumer views are holistic and multidimensional (Hoffman and Novak, 2018). The key dimensions of consumer experience concerning IoT solutions refer to behavioral, affective, sensory, intellectual, and social (Hoffman and Novak, 2018). Combining these components provides essential insights into consumers' precise mindset, which enables academics and practitioners to develop effective IoT solutions that can be applied in different contexts. The way in which consumers react to the introduction of specific IoT tools helps IT experts devise highly customized solutions that address consumer needs and expectations. Consumers tend to connect across different dimensions of IoT, mainly text, image, and audio. As a result, the created content can be properly analyzed to uncover specific network structures (Moradi and Dass, 2019; Parmar and Desai, 2016). It is important to identify specific maps in diverse segments of consumers to find recurring trends and parents related to their utilization of IoT applications. Academics and practitioners use such information to improve the functioning of IoT tools. 


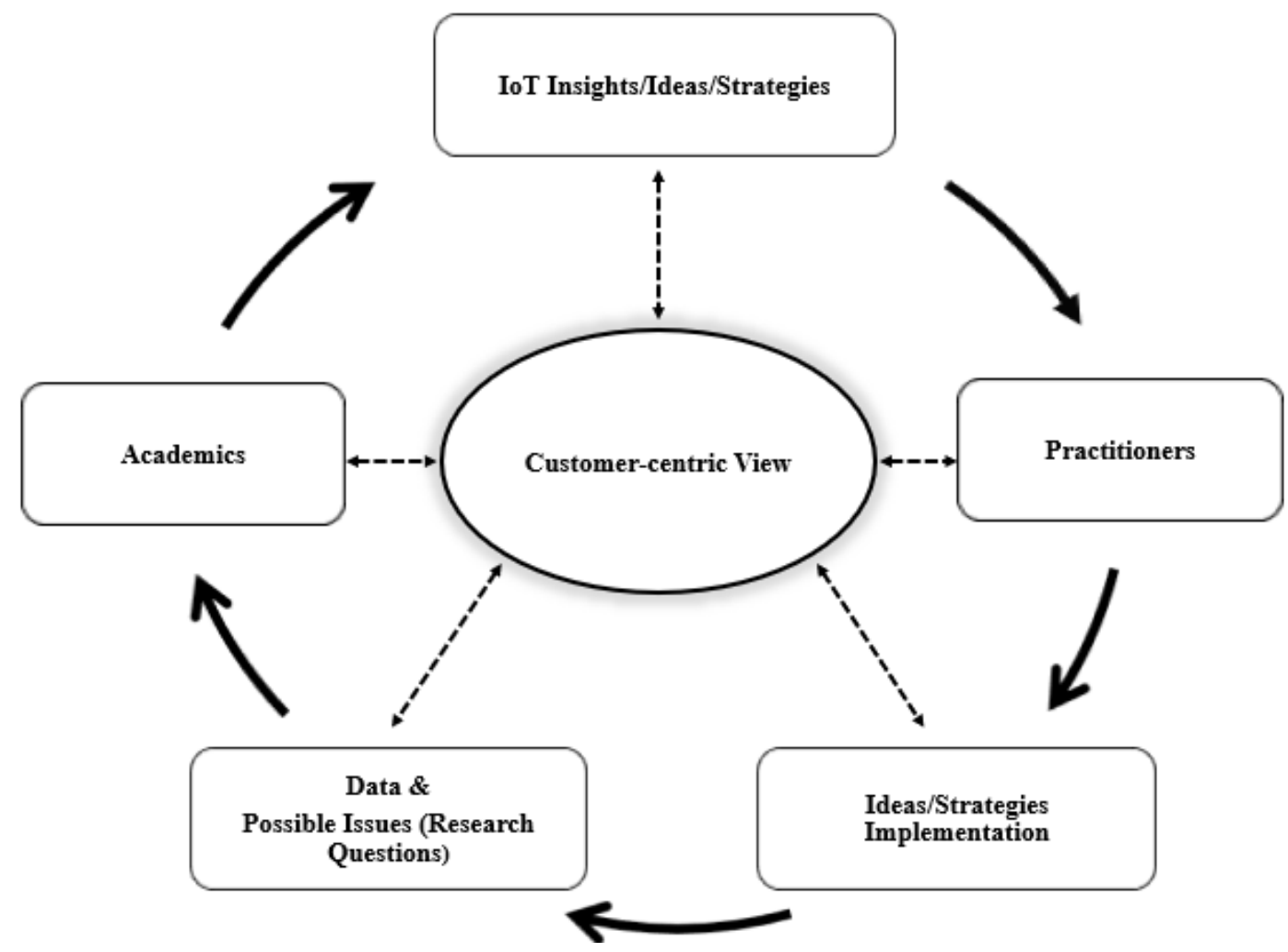

Figure 2. Academics and Practitioners Collaboration Process

Source: Developed by authors

The role of IoT in improving decision-making in marketing research is rather essential. IoT solutions have the potential to change marketing research. It is crucial to enhance individuals' understanding of how IoT tools can be used to their advantage (Marek and Wozniczka, 2017). The automatic production of real-time data flow helps marketing researchers determine effective strategies for positive customer interaction. The enhanced access to customer data facilitates academics and practitioners' decision-making capacity since the latter can be more confident in making well-informed decisions. The implementation of IoT solutions reveals numerous possibilities to enhance marketing research. It is particularly true for digital marketers who need access to substantial information on consumer trends and opinions pertaining to the consistent use of IoT solutions. Having more data to analyze is considered advantageous to digital marketers, as they can have an opportunity to streamline specific processes and reach to target consumer groups in diverse ways (Nguyen and Simkin, 2017). As a result of the direct connection between IoT and the cloud, the possibility to carry out predictive analysis of target customers' needs and preferences is evident.

Through exploring the diverse opportunities for analysis, digital marketers can incorporate relevant marketing and information systems insights into the consumer experience. The substantially increased use of IoT tools results in high quantitative data on consumption and customer experience (Al Hogail, 2018). As a result, the dimension of visibility would be additionally clarified in consumer experience of using IoT solutions and the cooperation between academics and practitioners (Wang et al., 2015). The interactions between individuals and things, along with refined information about the environment, will reach a new level of depth. The new dimension added to marketing will alter the way research is conducted on IoT in Customer Relationship Management (CRM). In considering the implications of consumer views on IoT solutions, experts in the field usually focus on disposition and situation factors. The dimension of disposition is related to important personal traits, particularly cognition or affect (Nicolescu et al., 2018). It helps clarify whether consumers can make rational purchasing decisions. The dimension of the situation illustrates the prevalence of contextual traits and refers to consumers' behavioral consistency (Nicolescu et al., 2018). The combination of these factors allows marketers to generate relevant insights into marketing research since consumer decision-making is an important part of individual views on the feasibility of IoT solutions.

5.3 Discussion of the challenges related to introducing IoT solutions. One of the challenges related to introducing IoT solutions is identified as addressing ethical and data privacy issues. It has been pointed out that these issues are rather complex and demanding than those involving the sole use of the Internet (Baldini et al., 2018). It can be explained by the fact that a substantial amount of data is generated during the 
development of IoT solutions, which raises the question of whether the respective information could be adequately managed (Maple, 2017). In establishing interaction with users, the focus is on respecting their needs and privacy rights. It necessitates the implementation of a transparent, ethical framework, which adequately regulatory process should support. An important part of the regulation of IoT solutions is described as obtaining informed consent. IoT applications seek informed consent from users so that individuals can be properly informed about sharing personal data (Baldini et al., 2018). Yet, adapting such regulations to the IoT context seems problematic considering the costs involved (Allhoff and Henschke, 2018). It occurs since regulations tend to impose additional burdens on the industry, and there is a high possibility that such burdens might reflect on users and their determination to utilize IoT solutions. Experts in the field provide several security measures to protect consumers in the complex IoT context. An effective strategy is recognized as a perception layer and is represented by access control and key management (Ouaddah et al., 2017).

The introduction of access control is associated with securing tags, while key management ensures forward and backward secrecy for an additional layer of security for users. Another security measure is described as a network layer, and it assumes that authentication is used to contribute to protecting users' personal information (Ouaddah et al., 2017). The application layer, which is the third essential security measure to address ethical and data privacy issues in IoT solutions, is determined by both technical and non-technical aspects. The technical components of the application layer are related to the protection of privacy, whereas the non-technical elements suggest enhanced user awareness of potential risks in the IoT context. An important consideration while addressing ethical risks in IoT solutions is adherence to the ethics code in making specific decisions (Moradi and Zihagh, 2019). From this perspective, it is advisable that users' benefit is always prioritized, which should be the main ethical concern of socially responsible organizations (Baldini et al., 2018). As a result, companies would be able to improve the multiple dimensions of IoT security. It can also lead to more satisfied consumers who would be further encouraged to use IoT tools. Furthermore, digital marketing professionals should use IoT tools ethically, as they need to gain consumers' trust. It is apparent that customers appreciate variety and customization while accessing specific IoT solutions, but marketers should consider that individuals value their privacy online and offline alike (Wang et al., 2015).

A significant challenge in this context is how to present personalized shopping experiences to consumers without being intrusive. Organizations need to align their digital marketing strategies with consumers' expectations for ethics and data privacy. The development of effective strategies might be challenging as a result of increased technology use. In this way, digital marketing professionals would most probably change consumer data utilization, which would be evident in their interaction with individuals. Thus, marketers should be strategically prepared for the forthcoming changes brought with the expanded utilization of IoT solutions (Rizza and Draetta, 2014). It is vital to convey a strong sense of trust and understanding of consumer characteristics. In the process of aligning better with consumers, digital marketing professionals can perceive IoT development as a significant driver to improve their long-term strategies.

\section{Conclusion}

This paper explored the implementation of IoT in marketing research. IoT solutions have emerged with their innovative capacities to help marketers change traditional marketing research activities and replace them with more comprehensive and accurate data analysis forms. It has been illustrated that the use of IoT tools contributed to enhancing the role and functions of information exchange in marketing research. Digital marketing professionals were enabled to use a wide range of IoT tools and strategies to refine their research and add new dimensions to marketing. The paper specified how the consistent use of IoT technologies resulted in substantial organizational competitiveness. Moreover, there was a discussion on the collaboration between academics and practitioners in developing IoT tools. It has been argued that such cooperation has been somewhat beneficial to the generation of relevant information that could be used to advance marketing research on IoT technologies. The insights shared by academics and practitioners also demonstrated specific trends in consumer experience about the utilization of IoT tools. However, the paper pointed out that the accumulation of important data is associated with the emergence of particular challenges that require a holistic approach to developing useful and competitive IoT tools. The major challenges related to introducing IoT solutions were described as ethical and data privacy issues. Undoubtedly, consumers in the digital era expect to be adequately protected, which would increase the rate of adopting IoT solutions. Future research might need to focus on ways to improve the collaboration between academics and practitioners to produce more conclusive results about the strategic direction for developing transparent and comprehensive IoT solutions.

Funding. There is no funding for this research. 


\section{References}

1. Al Hogail, A. (2018). Improving IoT technology adoption through improving consumer trust. Technologies, 6 , 64-80. https://doi.org/10.3390/technologies6030064.

2. Allhoff, F., Henschke, A. (2018). The Internet of Things: Foundational ethical issues. Internet of Things, 1-2, 55-66. https://doi.org/10.1016/j.iot.2018.08.005.

3. Angelova, N., Kiryakova, G., Yordanova, L. (2017). The great impact of Internet of Things on business. Trakia Journal of Sciences, 15(1), 406-412. https://doi.org/10.15547/tjs.2017.s.01.068.

4. Baldini, G., Botterman, M., Neisse, R., Tallacchini, M. (2018). Ethical design in the Internet of Things. Science and Engineering Ethics, 24(3), 905-925. https://doi.org/10.1007/s11948-016-9754-5.

5. Caro, F., Sadr, R. (2019). The Internet of Things (IoT) in retail: Bridging supply and demand. Business Horizons, 62(1), 47-54. https://doi.org/10.1016/j.bushor.2018.08.002.

6. Farooq, M.U., Waseem, M., Mazhar, S., Khairi, A., Kamal, T. (2015). A review on Internet of Things (IoT). International Journal of Computer Applications, 113(1), 1-7. https://doi.org/10.5120/19787-1571.

7. Gigli, M., Koo, S. (2011). Internet of Things, services and applications categorization. Advances in Internet of Things, 1, 27-31. https://doi.org/10.4236/ait.2011.12004.

8. Hoffman, D.L., Novak, T.P. (2018). Consumer and object experience in the Internet of Things: An assemblage theory approach. Journal of Consumer Research, 44(6), 1178-1204. https://doi.org/10.1093/jcr/ucx105.

9. Kosmatos, E.A., Tselikas, N.D., Boucouvalas, A.C. (2011). Integrating RFIDs and smart objects into a unified Internet of Things architecture. Advances in Internet of Things: Scientific Research, 1, 5-12. https://doi.org/10.4236/ait.2011.11002.

10.Lo, F.Y., Campos, N. (2018). Blending Internet-of-Things (IoT) solutions into relationship marketing strategies. Technological Forecasting and Social Change, 137, 10-18. https://doi.org/10.1016/j.techfore.2018.09.029.

11.Madakam, S., Ramaswamy, R., Tripathi, S. (2015). Internet of Things (IoT): A literature review. Journal of Computer and Communications, 3, 164-173. https://doi.org/10.4236/jcc.2015.35021.

12.Maple, C. (2017). Security and privacy in the Internet of Things. Journal of Cyber Policy, 2(2), 155-184. https://doi.org/10.1080/23738871.2017.1366536.

13.Marek, L., Wozniczka, J. (2017). The Internet of Things as a customer experience tool. Jagiellonian Journal of Management, 3, 163-176. https://doi.org/10.4467/2450114xjjm.17.011.9562.

14.Moradi, M., Badrinarayanan, V. (2021). The effects of brand prominence and narrative features on crowdfunding success for entrepreneurial aftermarket enterprises. Journal of Business Research, 124, 286-298. https://doi.org/10.1016/j.jbusres.2020.12.002.

15.Moradi, M., Dass, M. (2019). An investigation into the effects of message framing on crowdfunding funding level. Journal of Electronic Commerce Research, 20(4), 238-254. Available at: http://www.jecr.org/node/591.

16.Moradi, M., Dass, M., Pedada, K. (2017). An investigation into the role of brand affiliation and content emotions on crowdfunding success. Creating Marketing Magic and Innovative Future Marketing Trends, pp. 611-615, Springer, Cham. https://doi.org/10.1007/978-3-319-45596-9 116.

17.Moradi, M., Zihagh, F. (2019). Moderating effects of contextual and individual factors on the relationship between cultural precedents and marketing-related norms. Business Ethics and Leadership, 3(3), 39-46. https://doi.org/10.21272/bel.3(3).39-46.2019.

18.Nguyen, B., Simkin, L. (2017). The Internet of Things (IoT) and marketing: The state of play, future trends and the implications for marketing', Journal of Marketing Management, 33, 1-6. https://doi.org/10.1080/0267257X.2016.1257542.

19.Nicolescu, R., Huth, M., Radanliev, P., De Roure, D. (2018). Mapping the values of IoT. Journal of Information Technology, 33(4), 345-360. https://doi.org/10.1057/s41265-018-0054-1.

20.Orme, D. (2019). Can biometrics secure the Internet of Things? Biometric Technology Today, 5, 5-7. https://doi.org/10.1016/S0969-4765(19)30068-2.

21.Ouaddah, A., Mousannif, H., Elkalam, A.A., Ouahman, A.A. (2017). Access control in the Internet of Things: Big challenges and new opportunities. Computer Networks, 112, 237-262. https://doi.org/10.1016/j.comnet.2016.11.007.

22.Parmar, J.K., Desai, A. (2016). IoT: Networking technologies and research challenges. International Journal of Computer Applications, 154(7), 1-6. https://doi.org/10.5120/IJCA2016912181.

23.Pauget, B., Dammak, A. (2019). The implementation of the Internet of Things: What impact on organizations? Technological Forecasting and Social Change, 140. 140-146. https://doi.org/10.1016/j.techfore.2018.03.012. 
24.Rahman, A., Asyhari, A.T. (2019). The emergence of Internet of Things (IoT): Connecting anything, anywhere. Computers, 8, 40-43. https://doi.org/10.3390/computers8020040.

25.Ray, P.P. (2018). A survey on Internet of Things architectures. Journal of King Saud University-Computer and Information Sciences, 30(3), 291-319. https://doi.org/10.1016/j.jksuci.2016.10.003.

26.Rizza, C., Draetta, L. (2014). The "silence of the chips" concept: Towards an ethics (-by-design) for IoT. International Review of Information Ethics, 22, 23-31. https://doi.org/10.29173/irie125.

27.Stankovic, J.A. (2014). Research directions for the Internet of Things. IEEE, 1, 1-7. https://doi.org/10.1109/JIOT.2014.2312291.

28.Suh, D., Seo, C.W., Park, K.C. (2018). An urgent communication way of utilizing IoT sensor for the disabled. International Journal of Control and Automation, 11(3), 23-34. https://doi.org/10.14257/ijca.2018.11.3.03.

29. Vermesan, O., Friess, P. (2014). Internet of Things applications: From research and innovation to market deployment, Gistrup, Denmark: River Publishers. Available at: https://www.riverpublishers.com/pdf/ebook/RP_E9788793102958.pdf.

30.Wang, P., Valerdi, R., Zhou, S., Li, L. (2015). Introduction: Advances in IoT research and applications. Information Systems Frontiers, 17(2), 239-241. https://doi.org/10.1007/s10796-015-9549-2. 